\title{
EARLY AGE POROSITY AND PORE SIZE DISTRIBUTION OF CEMENT PASTE WITH FLUE GAS DESULPHURISATION (FGD) WASTE
}

\author{
Jamal M. KHATIB ${ }^{\mathrm{a}}$, Pritpal S. MANGAT ${ }^{\mathrm{b}}$, Lee WRIGHT ${ }^{\mathrm{c}}$ \\ ${ }^{a}$ Faculty of Science and Engineering, University of Wolverhampton, Wulfruna Street, \\ Wolverhampton, WVI $1 L Y$, UK \\ ${ }^{b}$ Centre for Infrastructure Management, MERI, Sheffield Hallam University, Howard Street, \\ Sheffield, S1 $1 \mathrm{WB}, \mathrm{UK}$ \\ ${ }^{c}$ Pick Everard, Halford House, Charles Street, Leicester, LE2 7DQ, UK
}

Received 21 Aug. 2012; accepted 27 Mar. 2013

\begin{abstract}
This paper is part of a wide-ranging investigation on the use of flue gas desulphurisation (FGD) waste in cement-based materials. It reports the results on the porosity and pore size distribution of cement paste containing varying amounts of simulated FGD waste. The water to binder ratio was 0.5 . The binder consists of cement and simulated FGD. The FGD is a combination of fly ash and gypsum ranging from $0 \%$ to $100 \%$. Cement in the pastes was partially replaced with $25 \%$ FGD (by weight). The porosity and pore size distribution of cement pastes was determined during the early stage of hydration. Increasing the amount of gypsum does not increase the pore volume. However, increasing the amount of gypsum in the paste leads to an increase in the threshold diameter and a decrease in the percentage of small pores in the paste, both indicating a coarser pore structure. The results of this investigation were compared with data at longer curing periods.
\end{abstract}

Keywords: clean coal technology; desulphurised waste; environment; flue gas desulphurisation (FGD) waste; porosity; pore size distribution; waste.

Reference to this paper should be made as follows: Khatib, J. M.; Mangat, P. S.; Wright, L. 2013. Early age porosity and pore size distribution of cement paste with flue gas desulphurisation (FGD) waste, Journal of Civil Engineering and Management 19(5): 622-627. http://dx.doi.org/10.3846/13923730.2013.793609

\section{Introduction}

The coal power industry generates a substantial amount of waste worldwide. Large amounts of harmful gases such as $\mathrm{CO}_{2}, \mathrm{SO}_{\mathrm{x}}$ and $\mathrm{NO}_{\mathrm{x}}$ are emitted into the atmosphere, thus causing environmental problems. Recently many countries in the world have adopted clean coal technology to reduce the impact of coalfired power stations on the environment. This technology involves the use of an alkali sorbent such as lime, which can react with the $\mathrm{SO}_{\mathrm{x}}$ gases to produce solid residues and thus preventing these gases to be emitted into the atmosphere. The solid residues are referred to as flue gas desulphurisation (FGD) waste. Depending upon the desulphurisation process, the FDG waste can range from pure gypsum to a combination of fly ash and gypsum (Mangat et al. 2006; Khatib et al. 2008). The European thermal power plants utilise brown and black coal resulting in a wide range of compositions of FGD waste. Typical FGD wastes from these plants give $\mathrm{SiO}_{2}$ contents in the range of $28.9-65.86 \%, \mathrm{Al}_{2} \mathrm{O}_{3}$ in the range of $10.71-31.9 \%, \mathrm{CaO}$ total in the range of $1.29-47.8 \%$ and $\mathrm{SO}_{3}$ in the range of $0.37-55.3 \%$ (Mangat et al. 2006). An optimum FGD composition based on strength and durability was found to be $85 \%$ fly ash and $15 \%$ gypsum providing a cement replacement of 25\% (Mangat et al. 2006). This optimum FGD composition represents an $\mathrm{SO}_{3}$ content of $8.87 \%$. It corresponds to siliceous and pozzolanic active fly ashes of $\mathrm{SO}_{3}$ content under $10 \%$ obtained from dry and semi-dry flue gas cleaning processes at many power plants in Europe. Examples of such FGD materials produced by power plants in Poland, Czech Republic, Slovak Republic and the Netherlands are given by Mangat et al. (2006). Pure gypsum can be used in the production of plaster board, whereas the majority of FGD consisting of gypsum and fly ash end up in landfill. This is not desirable as it raises concerns regarding the limited space of landfill sites and the impact on the environment.

Cement-based mortars and concrete are potential materials where the FGD waste can be incorporated.

Corresponding author: Jamal M. Khatib

E-mail: j.m.khatib@wlv.ac.uk 
Introducing FGD waste material into concrete will affect its properties and performance. These include porosity and pore size distribution. Porosity is a measure of accessible voids with respect to the total volume of the solid material. In addition to the volume of pores, it is also important to measure the pore structure according to pore diameter, extent and shape of the pores, all of which inevitably determine the performance and utilisation of materials. The strength and durability properties of materials such as concrete depend heavily on the amount of pores present as well as the size and distribution of such pores. The influence of porosity and pore size distribution on the physical, mechanical and durability properties is well documented (Odler, Rößler 1985; Fukaya et al. 1991; Mangat, Khatib 1992; Calleja 1986). Many attempts have been made to correlate porosity and pore structure with the performance of paste, mortar and concrete (Nyame, Illston 1980; Kolias 1994). The findings tend to indicate that strength is related to total porosity, whereas durability tends to be influenced more by pore structure.

The effects of fly ash and other mineral admixtures on porosity and pore structure of blended cement paste, with for example fly ash or slag, is well documented in the literature (Wee et al. 1995; Khatib, Mangat 1995; Singh, Garg 1996; Siddique, Khatib 2010; Hadjsadok et al. 2012). However, there is little information in the literature on the use of FGD residues in cement-based materials. If FGD wastes residues are to be used in construction materials such as concrete, the basic properties of concrete containing these wastes need to be determined. Among these properties are the porosity and pore size distribution. This paper is part of a wider investigation on the use of FGD wastes in concrete applications. It reports the results on porosity and pore size distribution of pastes containing simulated FGD at the age of 1 day of curing (i.e. during the early age of hydration). The results at longer curing ages are reported elsewhere (Khatib et al. 2013a, b). Simulated FGD was a combination of fly ash and gypsum. Mangat et al. (2006) showed that FGD can be simulated by mixing different combinations of fly ash and gypsum.

\section{Experimental}

\subsection{Materials}

The pastes used in this investigation consists of $42.5 \mathrm{~N}$ Portland cement (C), fly ash (FA), gypsum (G) and water. Table 1 presents the density and the specific surface of cement and FGD materials. Further information regarding the physical and chemical composition of the materials is given elsewhere (Khatib et al. 2013a, b). The water/binder was kept constant at 0.5 . The binder consists of cement, fly ash and gypsum. Paste $\mathrm{P} 1$ represents the reference paste
Table 1. Density and specific surface of materials

\begin{tabular}{lcc}
\hline & Density $\left(\mathrm{kg} / \mathrm{m}^{3}\right)$ & Specific surface $\left(\mathrm{m}^{2} / \mathrm{kg}\right)$ \\
\hline Cement & 3150 & 376 \\
Fly ash & 2180 & 355 \\
Gypsum & 2350 & 158 \\
\hline
\end{tabular}

containing $100 \%$ C. Mixes P2-P8 contain simulated FGD wastes consisting of different blends of fly ash and gypsum (FA-G blends). The cement was replaced with $25 \%$ FA-G blend. The gypsum content in the FA-G blends ranged from $0 \%$ (paste P2) to $100 \%$ (paste P8).

Table 2 shows the composition of binder in the various pastes. The basis for the proportions of the simulated FGD is reported elsewhere (Mangat et al. 2006; Khatib et al. 2008). The paste ID represents the proportions of replacement materials (i.e. fly ash and gypsum). For example, a paste with an ID 75FA25G represents a paste with replacement materials consisting of $75 \%$ fly ash and $25 \%$ gypsum.

\subsection{Mixing}

Fly ash and gypsum were mixed by hand until the homogeneity of the FA-G blends was achieved. All

Table 2. Constituents of binder

\begin{tabular}{|c|c|c|c|c|}
\hline \multirow[b]{2}{*}{$\begin{array}{l}\text { Paste } \\
\text { number }\end{array}$} & \multirow[b]{2}{*}{ Paste ID } & \multicolumn{3}{|c|}{ Proportions ( $\%$ weight of binder) } \\
\hline & & $\begin{array}{l}\text { Cement } \\
\text { (C) }\end{array}$ & $\begin{array}{l}\text { Gypsum } \\
\text { (G) }\end{array}$ & $\begin{array}{c}\text { Fly ash } \\
\text { (FA) }\end{array}$ \\
\hline $\mathrm{P} 1$ & $\operatorname{REF}\left(100_{\mathrm{C}}\right)$ & 100 & 0 & 0 \\
\hline $\mathrm{P} 2$ & $100_{\mathrm{FA}} 0_{\mathrm{G}}$ & 75 & 0 & 25 \\
\hline P3 & $95_{\mathrm{FA}} 5_{\mathrm{G}}$ & 75 & 1.25 & 23.75 \\
\hline $\mathrm{P} 4$ & $85_{\mathrm{FA}} 15_{\mathrm{G}}$ & 75 & 3.75 & 21.25 \\
\hline P5 & $75_{\mathrm{FA}} 25_{\mathrm{G}}$ & 75 & 6.25 & 18.75 \\
\hline P6 & $50_{\mathrm{FA}} 50_{\mathrm{G}}$ & 75 & 12.5 & 12.5 \\
\hline P7 & $20_{\mathrm{FA}} 80_{\mathrm{G}}$ & 75 & 20 & 5 \\
\hline P8 & $0_{\mathrm{FA}} 100_{\mathrm{G}}$ & 75 & 25 & 0 \\
\hline
\end{tabular}

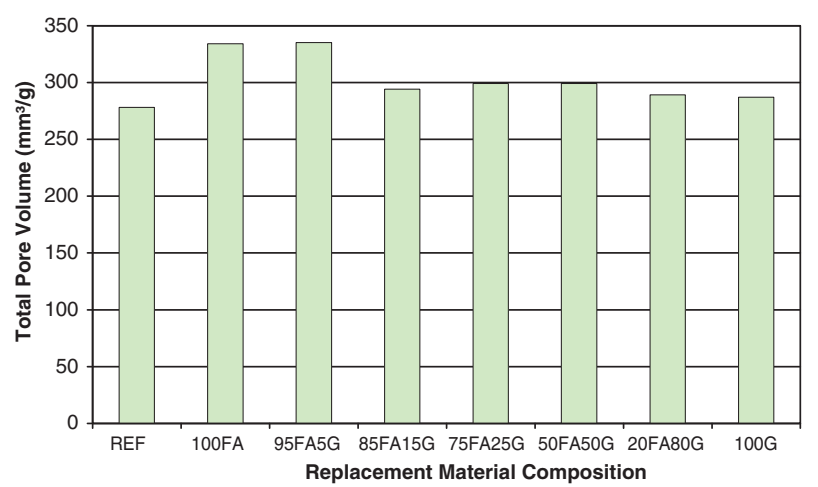

Fig. 1. Influence of FA-G composition on the TPV of pastes 
binder constituents were placed in a Hobart mixer and mixed for three minutes until the mixture was homogenous. The water was added over a period of 30 seconds while mixing continued for approximately 5 minutes. The mixing process was interrupted occasionally to remove accumulated material from the paddle and the bottom of the bowl. After five minutes of mixing, the paste was mixed by hand to remove any accumulated material on the paddle and the base of the mixing bowl. The material was regularly remixed during sample preparation to avoid settlement and bleeding.

\subsection{Testing}

The paste specimens consisted of $50-\mathrm{mm}$ cubes. All pastes were placed in a mist curing room at $20 \pm 1{ }^{\circ} \mathrm{C}$ and $95 \pm 5 \%$ relative humidity for 24 hours. After that, demoulding took place and cubes were crushed for compressive strength and representative samples were taken from the middle of the crushed cube for the determination of porosity and pore size distribution. The sample size used for the analysis was approximately $1 \mathrm{~g}$. The samples were dried in an oven at $70{ }^{\circ} \mathrm{C}$ for 48 hours to remove the internal moisture. The samples were then placed in an airtight

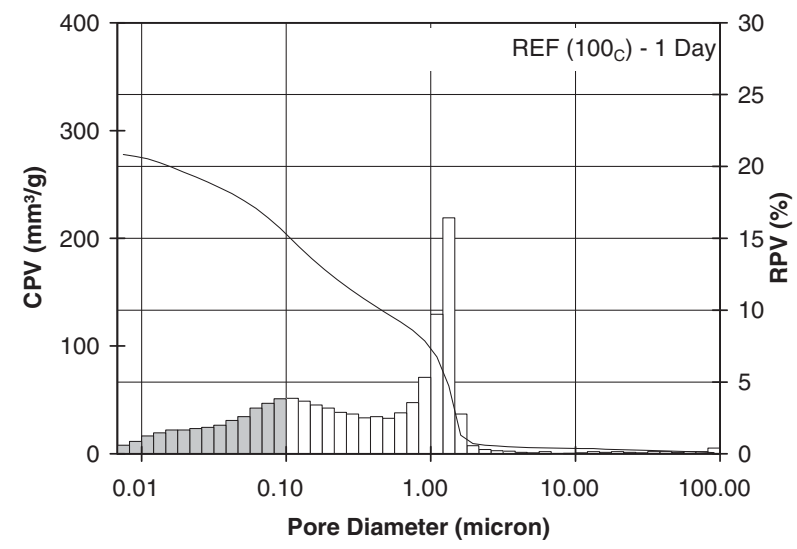

Fig. 2. Pore size distribution of the reference paste P1

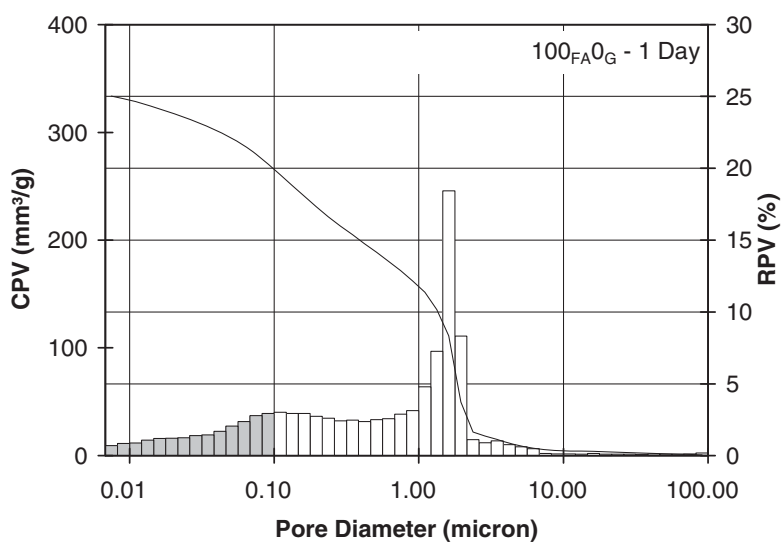

Fig. 3. Pore size distribution of paste $\mathrm{P} 2$ bottle until testing. Silica gel crystals were added to the bottle to absorb any moisture. The total pore volume (TPV) (i.e. porosity) and pore size distribution were determined using the mercury intrusion porosimetry technique. Further information on the testing technique is found elsewhere (Khatib, Wild 1996; Khatib, Mangat 1999, 2003).

\section{Results}

Figure 1 shows the TPV of paste containing different FA-G blends at 1 day. The TPV of the FA-G blended pastes (P2-P8) tends to be higher than that exhibited by the reference paste (P1). Pastes $\mathrm{P} 2$ and $\mathrm{P} 3$ which contain the highest amount of fly ash in the FA-G blend $(100 \%$ and $95 \%$, respectively) record the highest TPV.

Figures 2-9 show the pore size distribution for pastes P1-P8, respectively, at 1 day of curing (i.e. after demoulding). The shape of the pore distribution curves during the early periods of hydration look similar with and without simulated FGD waste. This is different from the pore size distribution at later ages of hydration (Khatib et al. 2012a, b, 2013a, b) where the presence of increasing amounts of simulated FGD shows the emergence of secondary peaks. Figure 10 shows a typical pore size distribution curve at 365 days of curing for

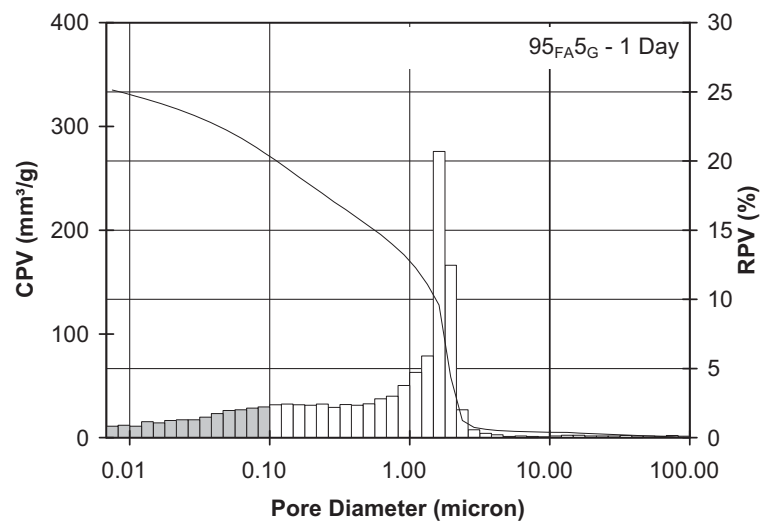

Fig. 4. Pore size distribution of paste P3

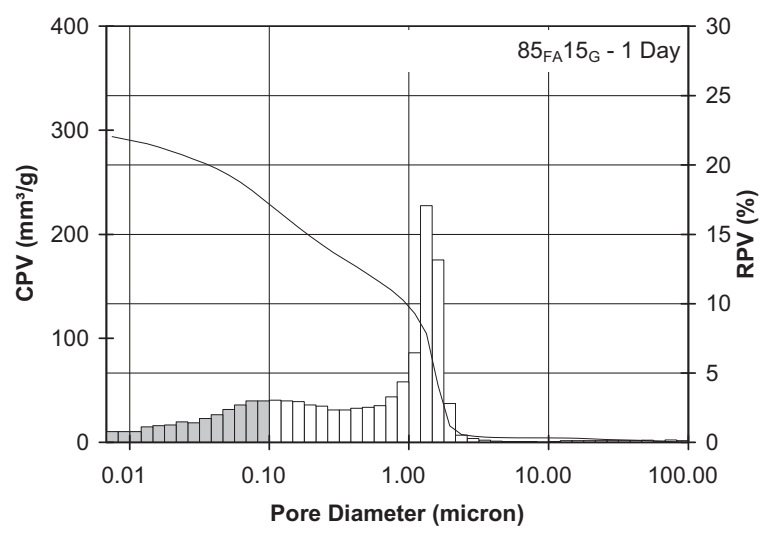

Fig. 5. Pore size distribution of paste $\mathrm{P} 4$ 


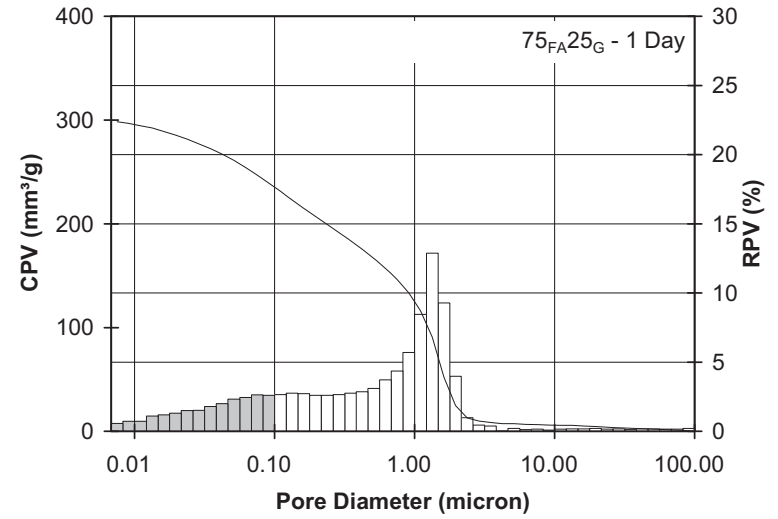

Fig. 6. Pore size distribution of paste P5

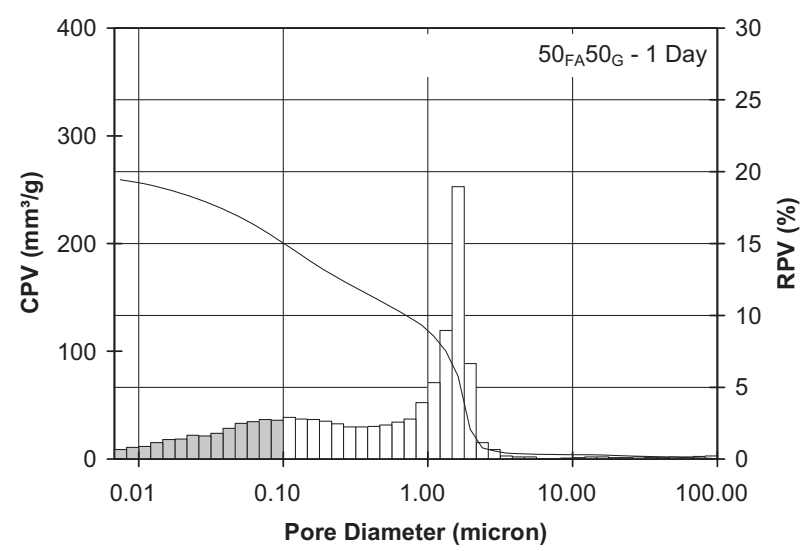

Fig. 7. Pore size distribution of paste P6

FA-G composition of 80-20 (Khatib et al. 2012b), where the emergence of a secondary peak is more apparent.

Figure 11 shows the threshold diameter (TD) for mixes containing different FA-G blends. The TD is the diameter before which the pore size distribution curve rises sharply. An increase in the TD tends to indicate a coarser pore structure. The reference mix exhibited a TD of $1.65 \mu \mathrm{m}$. Replacing cement with $25 \%$ fly ash $\left(100_{\mathrm{FA}} 0_{\mathrm{G}}\right)$ increased the TD to more than $2.25 \mu \mathrm{m}$. Replacing the fly ash with $5 \%$ of gypsum increased the

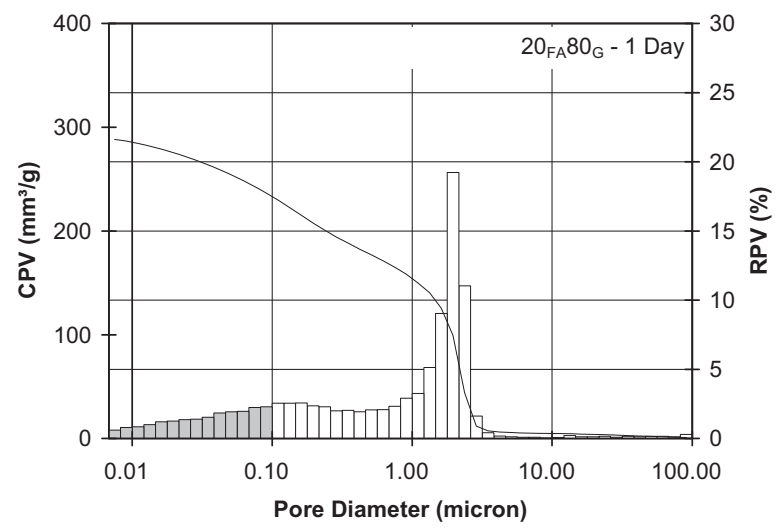

Fig. 8. Pore size distribution of paste P7

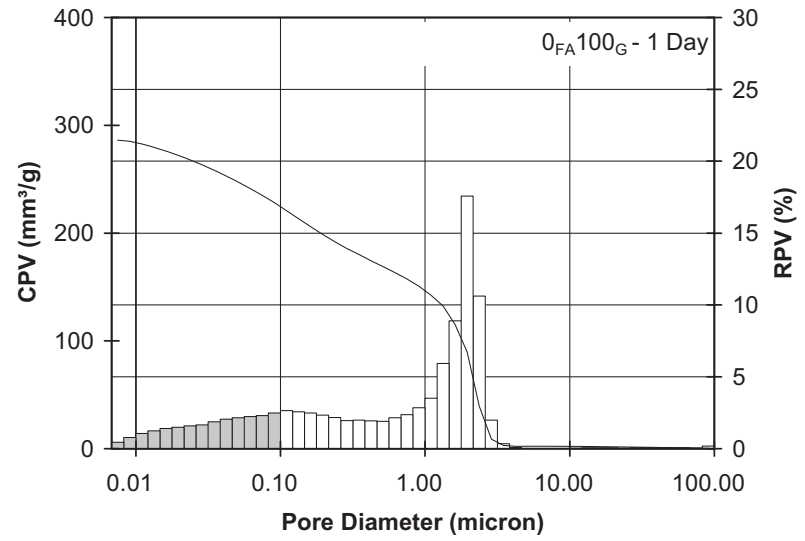

Fig. 9. Pore size distribution of paste $\mathrm{P} 8$

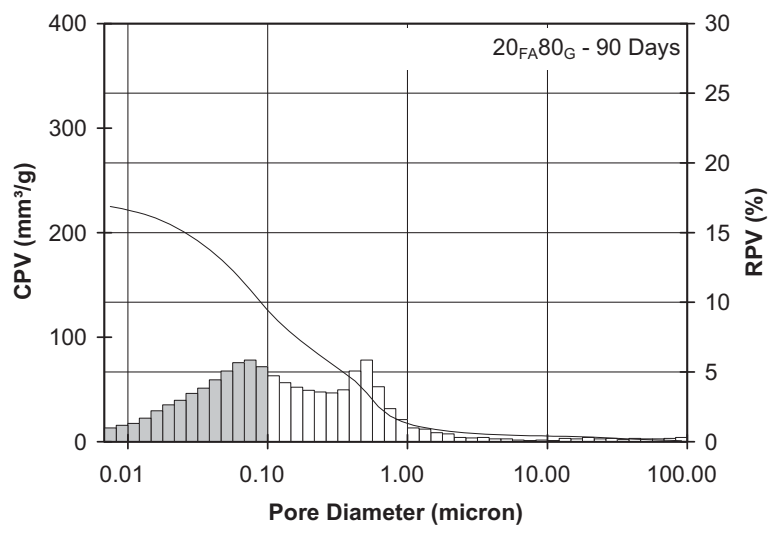

Fig. 10. Pore size distribution of paste P7 at 90 days of curing (Khatib et al. 2012b)

TD. The TD for pastes $\mathrm{P} 4\left(85_{\mathrm{FA}} 15_{\mathrm{G}}\right)$ and $\mathrm{P} 5\left(75_{\mathrm{FA}} 25_{\mathrm{G}}\right)$ was lower than the other pastes containing fly ash and gypsum and was similar to the control (P1).

The percentage of small pores (i.e. pores whose diameter is smaller than $0.1 \mu \mathrm{m}$ ) for the various pastes is shown in Figure 12. All pastes with fly ash and gypsum (pastes P2-P8) show a lower percentage of small pores indicating a coarser pore structure in the presence of simulated FGD products. However, gypsum contents replacing more than $5 \%$ of the fly ash start showing a higher percentage of small pores compared with paste P3 $(95 \mathrm{FA} 5 \% \mathrm{G})$ but the trend is not very strong.

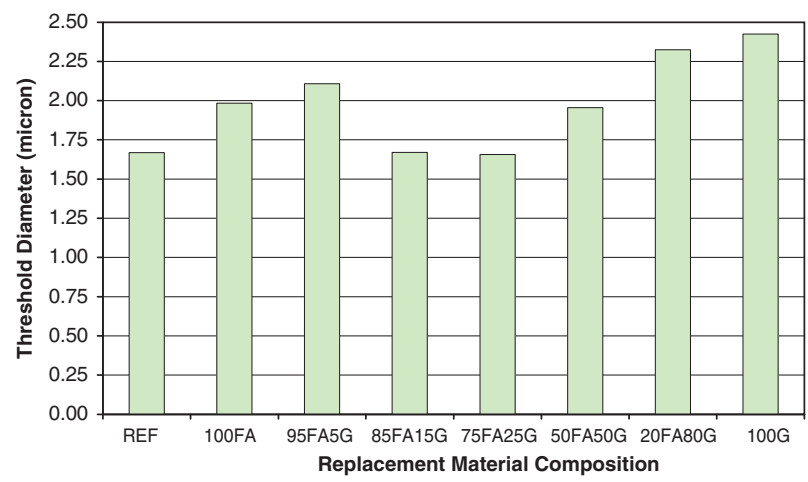

Fig. 11. Influence of simulated FGD on the TD of pastes 


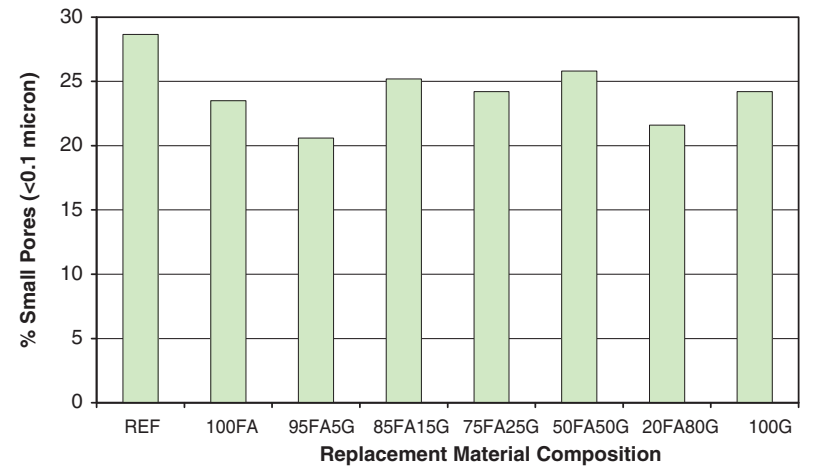

Fig. 12. Influence of simulated FGD on the percentage of small pores $(<0.1 \mathrm{~m})$ of pastes

\section{Discussion of results}

Manmohan and Mehta (1981) reported that replacing cement with fly ash increased pore refinement compared to a reference mix of $100 \%$ cement after a certain period of hydration. This was attributed to the pozzolanic properties of the fly ash. The calcium hydroxide $(\mathrm{CH})$ released during cement hydration reacts with the silica and alumina components of the fly ash to form additional hydrated phases. These products fill the open capillary pores, which result in an improvement in the pore structure (Ramezanianpour, Malhotra 1995; Xu, Huang 1992). However, in the present investigation, the pastes were cured only for one day and the production of $\mathrm{CH}$ in this period would be very limited for sufficient reaction to take place between the fly ash particles and $\mathrm{CH}$. At 7, 28 and 90 days of curing, the trend is noticeably different (Khatib et al. 2012b, 2013a, b).

Using gypsum in cement-fly ash paste enhances the reactivity of fly ash particles (Uchikawa 1986; Wild et al. 1995). This was attributed to the formation of sulphate containing C-A-S-H products that form around the fly as particles. However, at 1 day, this was not evident in the present study. Long-term data are reported elsewhere (Khatib et al. 2011) which show the effect more clearly. Excessive replacement of fly ash with gypsum can result in a retardation of the hydration process as the increased ettringite formation on the fly ash particles temporarily retards the reaction of fly ash with lime (Wild et al. 1995). This does appear to be the case, especially in the mix containing $100 \%$ gypsum as replacement blend (i.e. paste P8). The gypsum in the FGD waste produces ettringite in the early ages of hydration coating the fly ash particles and thereby delaying the pozzolanic reaction. In the longer term, the continued ettringite formation fills the pore spaces which may be the reason for the secondary peak on the pore distribution curve. The ettringite provides enhanced sulphate resistance to FGD blended systems (Khatib et al. 2008). This makes the FGD materials particularly suitable for sulphate resistance applications.

\section{Conclusions}

The following conclusions are based on the results of this investigation:

1) Replacing $25 \%$ of cement with different simulated desulphurised waste (FA-G blends) increased the TPV of cement pastes at 1 day of curing. Increasing the gypsum content in the FA-G blend generally increased TPV. Replacing cement with different FA-G blends increased the TD and decreased the percentage of small pores below $0.1 \mu \mathrm{m}$ (SP), which indicated a decrease in pore refinement compared to the reference paste.

2) Concrete incorporating FGD waste has the potential for use in various applications including masonry blocks and paving slabs. Also, using FGD waste in concrete results in superior sulphate resistance and thereby enhanced durability. This suggests that it can be a suitable material for ground structures.

\section{Acknowledgements}

The authors gratefully acknowledge the support from the European Commission for the Copernicus project on the utilisation of FGD waste in building materials.

\section{References}

Calleja, J. 1986. Future trends in the research of the structure, properties and behaviour of blended cements, in The 8th International Congress on the Chemistry of Cement, September, 1986, Rio de Janeiro, Brazil, Vol. 1: 233-248.

Fukaya, Y.; Hoshihara, H.; Mizukami, Y. 1991. Effect of particle size distribution on the structure and strength of cement paste, in CAJ Proceedings of Cement and Concrete 45: 92-97.

Hadjsadok, A.; Kenai, S.; Courard, L.; Michel, F.; Khatib, J. M. 2012. Durability of mortar and concretes containing slag with low hydraulic activity, Cement and Concrete Composites 34(5): 671-677. http://dx.doi.org/10.1016/j.cemconcomp.2012.02.011

Khatib, J. M.; Mangat, P. S. 1995. Absorption characteristics of concrete as a function of location relative to the casting position, Cement and Concrete Research 25(5): 999-1010. http://dx.doi.org/10.1016/0008-8846(95)00095-T

Khatib, J. M.; Mangat, P. S. 1999. Influence of superplasticiser and curing on porosity and pore structure of cement paste, Cement and Concrete Composites 21(5-6): 431-437. http://dx.doi.org/10.1016/S0958-9465(99)00031-1

Khatib, J. M.; Mangat, P. S. 2003. Porosity of cement paste cured at $45^{\circ} \mathrm{C}$ as a function of location relative to casting position, Cement and Concrete Composites 25(1): 97-108. http://dx.doi.org/10.1016/S0958-9465(01)00093-2

Khatib, J. M.; Mangat, P. S.; Wright, L. 2008. Sulphate resistance of blended binders containing FGD waste, in Proceedings of the Institution of Civil Engineers (ICE) - Construction Materials 161(3): 119-128. 
Khatib, J. M.; Wild, S. 1996. Pore size distribution of metakaolin paste, Cement and Concrete Research 26(10): 1545-1553. http://dx.doi.org/10.1016/0008-8846(96)00147-0

Khatib, J. M.; Wright, L.; Mangat, P. S. 2011. Influence of incorporating flue gas desulphurisation (FGD) residues on porosity and pore size distribution of cement paste, e-Journal of New World Sciences Academy (NWSA) 6(4): 1676-1682.

Khatib, J. M.; Wright, L.; Mangat, P. S. 2012a. Porosity and pore size distribution of well hydrated cement-fly ashgypsum pastes, American-Eurasian Journal of Scientific Research 7(4): 142-145.

Khatib, J. M.; Wright, L.; Mangat, P. S. 2012b. Effect of gypsum on the pore size distribution of fly ash-cement paste at 90 days of curing, in International Scientific Conference "Auezov Reading - 11: Kazakhstan on the way of social education: Innovative directions of research, education and culture", 6-7 December, 2012, Auezov South Kazakhstan State University, Shymkent, Kazakhstan.

Khatib, J. M.; Wright, L.; Mangat, P. S. 2013a. Effect of fly ashgypsum blend on porosity and pore size distribution of cement pastes, Advances in Applied Ceramics 112(4): 197201. http://dx.doi.org/10.1179/1743676112Y.0000000032

Khatib, J. M.; Wright, L.; Mangat, P. S. 2013b. Pore size distribution of pastes containing fly ash-gypsum blends cured for 7 days, KSCE Journal for Civil Engineering 112(4): 197-201.

Kolias, S. 1994. Investigation of the possibility of estimating concrete strength by porosity measurements, Materials and Structures 27: 265-272. http://dx.doi.org/10.1007/BF02473043

Mangat, P. S.; Khatib, J. M. 1992. Influence of initial curing on pore structure and porosity of blended cement concretes, in Proc. of the 4th International Conference on Flay Ash, Slag and Natural Pozzolans in Concrete, Vol. 1, 813-833.

Mangat, P. S.; Khatib, J. M.; Wright, L. 2006. Optimum utilisation of flue gas desulphurisation (FGD) waste in blended binder for concrete, in Proc. of the Institution of Civil Engineers - Construction Materials Journal 1(2): 60-68.

Manmohan, D.; Mehta, P. K. 1981. Influence of pozzolanic, slag, and admixtures on pore size distribution and permeability of hardened cement pastes, Cement, Concrete and Aggregates 3(1): 63-67. http://dx.doi.org/10.1520/CCA10203J

Nyame, B. K.; Illston, J. M. 1980. Capillary pore structure and permeability of hardened cement paste, in The $7 \mathrm{th}$ International Congress on the Chemistry of Cement, 1980, Paris, France, Vol. 6, 181-185.

Odler, I.; Rößler, M. 1985. Investigation on the relationship between porosity, structure and strength of hydrated Portland cement paste. II. Effect of pore structure and of degree of hydration, Cement and Concrete Research 15(3): 401-410. http://dx.doi.org/10.1016/0008-8846(85)90113-9

Ramezanianpour, A. A.; Malhotra, V. M. 1995. Effect of curing on the compressive strength, resistance to chloride-ion penetration and porosity of concretes incorporating slag, fly ash or silica fume, Cement and Concrete Composites 17(2): 125-133. http://dx.doi.org/10.1016/0958-9465(95)00005-W

Siddique, R.; Khatib, J. M. 2010. Mechanical properties and abrasion resistance of HVFA concrete, Materials and Structures, RILEM Journal 43(5): 709-718. http://dx.doi.org/10.1617/s11527-009-9523-x

Singh, M.; Garg, M. 1996. Relationship between mechanical properties and porosity of water-resistant gypsum binder, Cement and Concrete Research 26(3): 449-456. http://dx.doi.org/10.1016/S0008-8846(96)85032-0

Uchikawa, H. 1986. Effect of blending components on the hydration and structure formation, in The 8th International Congress on the Chemistry of Cement, September, 1986, Rio de Janeiro, Brazil, Vol. 1: 249-259.

Wee, T. H.; Matsunaga, Y.; Watanabe, Y.; Sakai, E. 1995. Microstructure and strength properties of high strength concretes containing various mineral admixtures, Cement and Concrete Research 25(4): 715-720. http://dx.doi.org/10.1016/0008-8846(95)00061-G

Wild, S.; Hadi, M.; Khatib, J. 1995. The influence of gypsum content on the porosity and pore-size distribution of cured PFA-lime mixes, Advances in Cement Research 7: 47-45. http://dx.doi.org/10.1680/adcr.1995.7.26.47

Xu, L. P.; Huang, S. Y. 1992. Relationship between strength and porosity of fly ash cement pastes, in The 9th International Congress on the Chemistry of Cement, 1992, New Delhi, India, 337-342.

\begin{abstract}
Jamal M. KHATIB. Professor of Civil Engineering (Construction/Structural Materials) - Faculty of Science and Engineering at the University of Wolverhampton, UK. Prior to the present post, he was a Senior Lecturer at Sheffield Hallam University and Research fellow at the Universities of Glamorgan and Aberdeen. He obtained his M.Sc. in Structural Engineering from Liverpool University and $\mathrm{PhD}$ in Concrete/Structural Materials from Aberdeen University. His research area is in the general field of construction materials and management and the use of industrial by-product, waste, recycled and novel materials in construction. He published more than 200 papers in the field of sustainable construction materials. He has an ISI Web of Knowledge H-index of 15 and more than 1400 citations.
\end{abstract}

Pritpal S. MANGAT. Professor and Director of the Centre for Infrastructure Management at Sheffield Hallam University, UK. He is a member of ACI committees 544 Fibre Reinforced Concrete and 369 Rehabilitation. His research interests include novel construction materials derived from waste, development of low-voltage heating systems for accelerated curing of concrete. He published widely in the above mentioned areas.

Lee WRIGHT. Consulting Structural Engineer with Pick Everard, UK. He obtained his PhD in 2002 from Sheffield Hallam University. His research interests include the mechanical and durability properties of concrete containing desulphurised (FGD) waste. 